Research Article

\title{
Investigation on Computing Method of Martian Dust Fluid Based on the Energy Dissipation Method
}

\author{
Tianxiang Ding $\mathbb{D}^{1},{ }^{1}$ Xuyan Hou $\mathbb{D},{ }^{1}$ Man Li $\mathbb{D}^{2},{ }^{2}$ Guangyu Cao $\mathbb{D}^{1},{ }^{1}$ Jixuan Liu $\left(\mathbb{D},{ }^{1}\right.$ \\ Xianlin Zeng $\mathbb{D}^{1},{ }^{1}$ and Zongquan Deng $\mathbb{D}^{1}$ \\ ${ }^{1}$ State Key Laboratory of Robotics and System, Harbin Institute of Technology, No. 2 Yikuang Street, Nangang, Harbin City, \\ Heilongjiang Province, China 150080 \\ ${ }^{2}$ Beijing Institute of Spacecraft Environment Engineering, China Academy of Space Technology, No. 104 Youyi Street, Haidian, \\ Beijing, China 100094
}

Correspondence should be addressed to Xuyan Hou; houxuyan@hit.edu.cn

Received 14 January 2020; Accepted 2 May 2020; Published 23 May 2020

Academic Editor: Hikmat Asadov

Copyright $\odot 2020$ Tianxiang Ding et al. This is an open access article distributed under the Creative Commons Attribution License, which permits unrestricted use, distribution, and reproduction in any medium, provided the original work is properly cited.

In this paper, an initiative Martian dust fluid simulating research based on the energy dissipation method was developed to simulate the deposition process of Martian dust fluid which was caused by surface adhesion between particles and Martian rovers. Firstly, an energy dissipation model of particles based on the Discrete Element Method (DEM) was established because of the characteristics of Martian dust particles such as tiny size and viscoelasticity. This model is based on the existing DMT model to analyze the collision deposition of dust fluid particles, including particle-spacecraft collision and particle-particle collision. Secondly, this paper analyzed the characteristics of particles after their first collision, then, established the stochastic model of critical wind speed for the particle deposition process. Finally, a series of simulations of the Martian dust fluid particle deposition process were done based on DEMCFD. The results verified the accuracy of the energy dissipation model and the stochastic model, which could also verify the feasibility and effectiveness of the computing method of Martian dust fluid based on the DEM-CFD technology.

\section{Introduction}

A global dust storm (GDS) occurred in Mars year (MY) 34 (2018). According to the observation from the MSL Curiosity rover, the daily maximum UV radiation in the Gale Crater decreased by $90 \%$ from sols 2075 (opacity 1) to sols 2085 (opacity 8.5) $[1,2]$. Figure 1(a) are two views from NASA's Curiosity rover showing that dust has significantly increased over three days from June 7 th to June 10th. Figure 1(b) shows a series of views from the Opportunity rover with darkening Martian sky, while the right side was Opportunity's worst visibility in the MY34 GDS.

Due to the low solar radiation, the solar-powered Opportunity rover (MER-B) was forced to shut down since June 10th of 2018, and eventually led to the end of the MER mission. In fact, local and regional dust storms are ubiquitous on Mars. Every few Mars years, regional dust storms grow and merge to become a global dust storm (GDS). Lisano and Bernard created a timeline of dust storm observations, which is shown in Figure 2. The timeline includes all major planetencircling and regional dust storms, which were observed by Mars orbiters, by Mars landers or by telescopes from the Earth, from 1971 to 2013 (the MY9 to the MY31) [3-7]. According to limited GDS samples, a GDS occurred every three Mars years on average.

Martian dust particles lifted by Martian aeolian activities may cause serious challenge to Martian rovers. These fine powders, which are mainly crushed basaltic materials, may cause performance degradation and other issues of optics to the rovers [8-16]. The Opportunity rover was hit by the MY28 GDS in 2007 when it carried on exploring operations in the Victoria Crater. During the peak of the storm, power output from the solar panels was reduced over $80 \%$, which led to two weeks of minimal operations, including several 


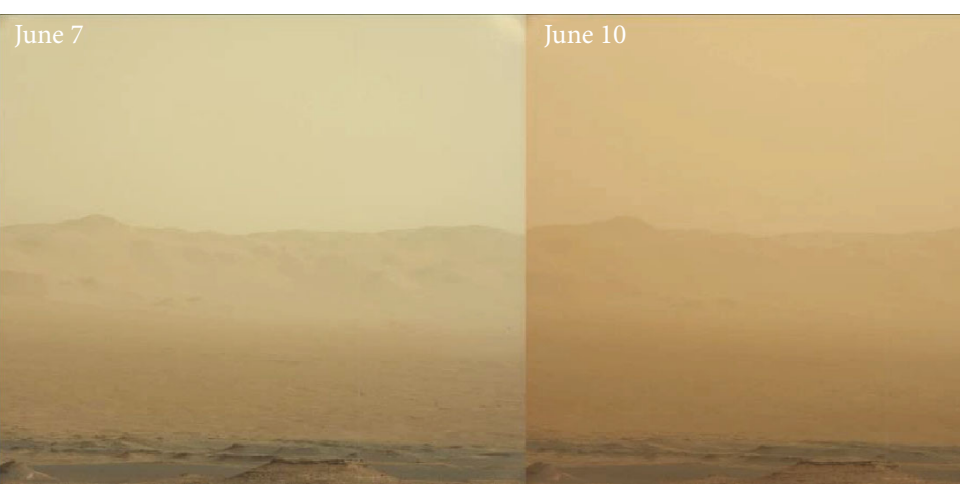

(a)

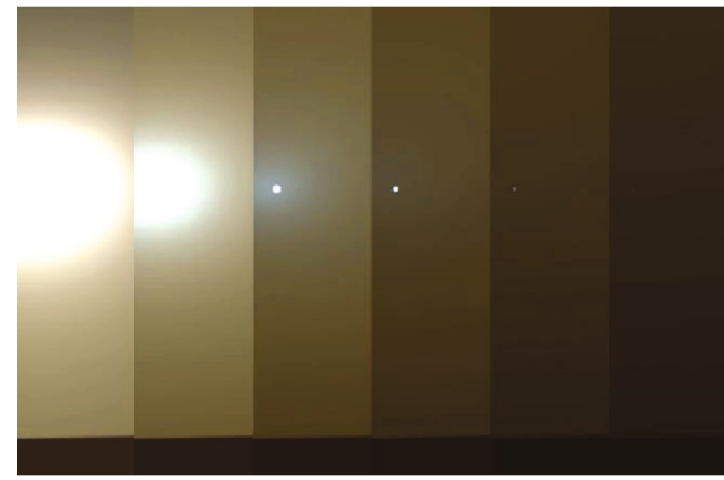

(b)

Figure 1: Views of the MY34 GDS from Martian rovers: (a) Curiosity's view of the MY34 GDS; (b) Opportunity's view of the MY34 GDS.
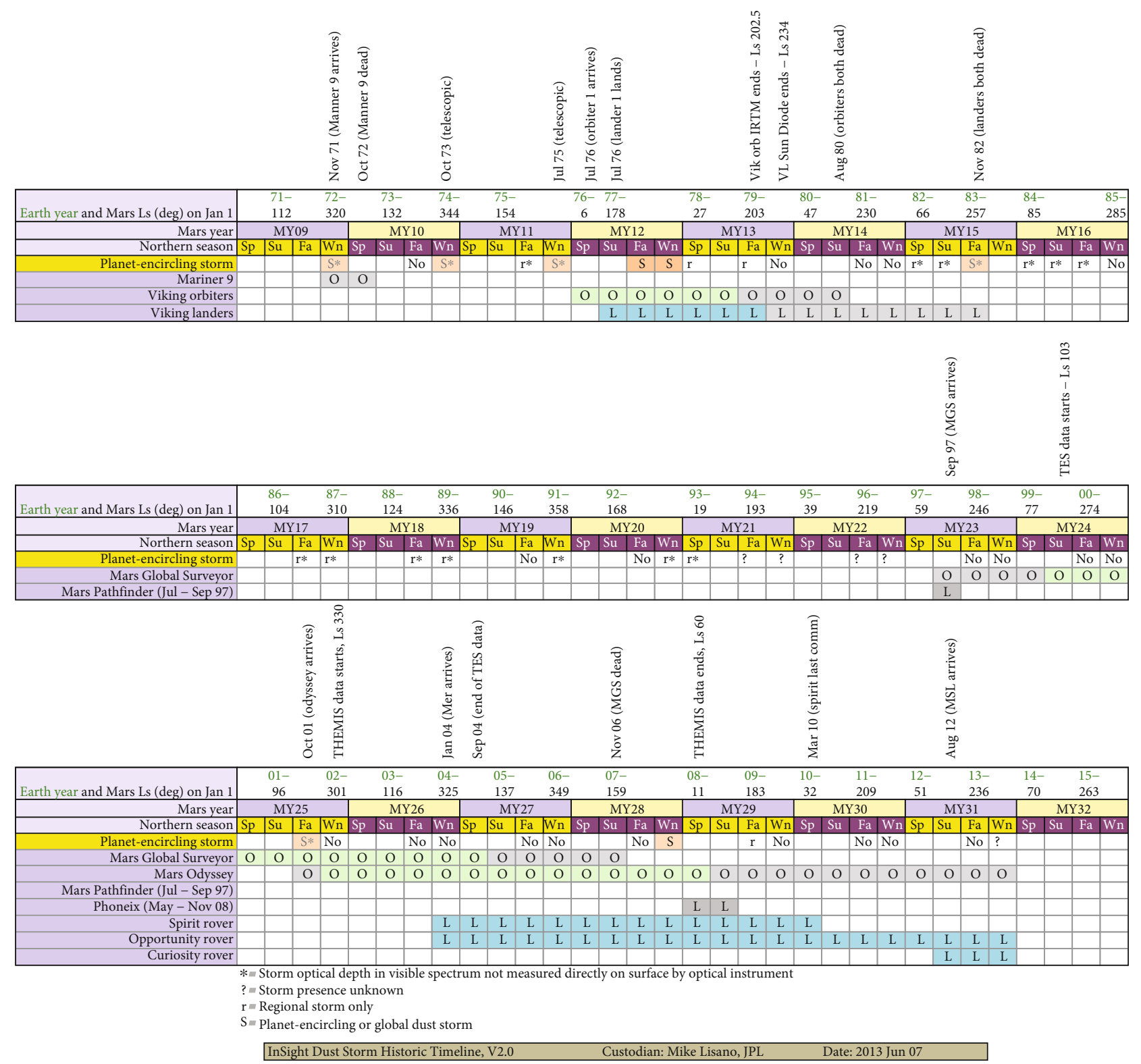

Figure 2: The Dust Storm Historic Timeline from the MY9 to the MY31 [3] 


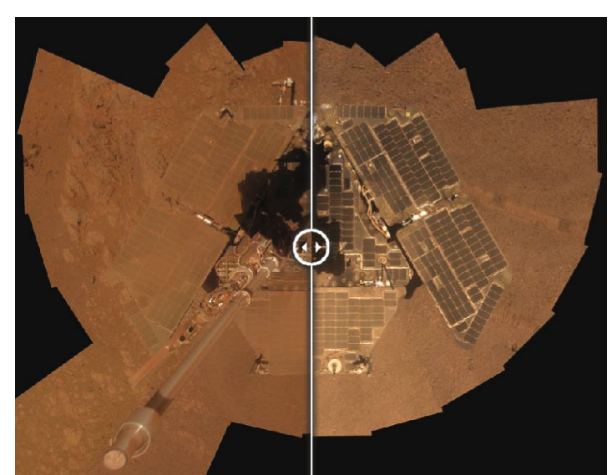

Figure 3: Comparison of Opportunity's solar panels before and after the MY28 GDS.

days with no contact from the rover to save power [17]. Figure 3 shows the comparison of Opportunity's solar panels before and after the dust storm. The suspended dust dropped onto solar panels and polluted solar panels seriously, which caused a serious challenge to the rover's power supply [18].

The deposition process of Martian dust is a typical twophase flow process, but it is difficult to solve the equations of these phenomena directly. Therefore, the numerical approach has become an effective tool to study the gas-solid two-phase flow. In recent years, the numerical approach based on DEM-CFD is widely used for the industrial twophase flow process, such as pneumatic conveying and gassolid fluidization [19-32]. Thus, the numerical approach based on DEM-CFD is applicable for the research on the effect of the Martian dust storm. In this paper, an initiative Martian dust fluid simulating research based on the energy dissipation method was developed to simulate the deposition process of Martian dust fluid which was caused by surface adhesion between particles and Martian rovers. Importantly, this study provides a theoretical basis for Martian dust protection and the Martian exploration mission.

\section{Materials and Methods}

2.1. Energy Dissipation of Martian Dust Collision Process. The energy dissipation of collision is the major cause of the deposition process of Martian dust particles. The deposition process can be divided into two categories: the collision with the Martian rover's surface and the collision with the grain bed, which is shown in Figure 4. In this paper, the energy dissipation of collision is defined as the combined effect of adhesion energy loss and damping energy loss, and the contact status of Martian dust particles is analyzed based on the DMT contact model [33].

According to the DMT contact model, the contact process is divided into two parts: the loading process and the unloading process. The loading process starts from the generation of the normal displacement until the normal displacement reaches the maximum. The unloading process starts from the maximum normal displacement until the normal displacement goes back to 0 . However, due to the effect of the Van der Waals force, the Martian dust particle is applied to a negative contact force in the unloading process when the normal displace is 0 . Figure 5 shows the contact force in the loading-unloading process, while the shaded part in Figure 5 is the adhesion energy loss of the collision process.

According to the DMT contact model [34, 35], the particle contact force in the loading process meets the following rule.

$$
a^{3}=\frac{3 R^{*}}{4 E^{*}} F .
$$

In equation (1), $F$ is the normal contact force, $a$ is the contact surface radius, and $\delta$ is the normal displacement.

The particle contact force in the unloading process meets the following rule.

$$
a^{3}=\frac{3 R^{*}}{4 E^{*}}\left(F+2 \pi \Delta \gamma^{*} R^{*}\right) .
$$

While the contact surface radius $a$ and the normal displacement $\delta$ meet the following rule.

$$
\delta=\frac{a^{2}}{R^{*}} .
$$

In the above equations, $R^{*}=\left[1 / R_{1}+1 / R_{2}\right]^{-1}$ is the combined radius of contacted spheres, $E^{*}=\left[\left(1-v_{1}^{2}\right) / E_{1}+(1-\right.$ $\left.\left.v_{2}^{2}\right) / E_{2}\right]^{-1}$ is the combined elastic modulus of two contacted spheres, where $v_{i}$ and $E_{i}$ are Poisson's ratios and elastic modulus of two particles, respectively.

While analyzing the collision between the Martian dust particle and the Martian rover's surface, $R_{1}=r_{1}$ is the curvature radius of the contact point $\mathrm{A}, R_{2}$ is the curvature radius of the surface. Thus,

$$
R_{1}^{*}=\left.\frac{R_{1} R_{2}}{R_{1}+R_{2}}\right|_{R_{1}=r_{1}, R_{2}=+\infty}=r_{1} \text {. }
$$

According to equation (2), the adhesion energy loss is not related to the magnitude and direction of the particle velocity, but related to the contact surface energy $\Delta \gamma^{*}$, the combined elastic modulus $E^{*}$, and the combined radius of contacted spheres $R^{*}$. Thus, the adhesion energy loss at the contact point A of the first collision (as shown in Figure 4) can be calculated as follows.

$$
\begin{aligned}
W_{A v}= & \int_{\delta_{0}}^{\delta_{A \max }} \frac{4 E^{*}}{3 r_{1}} a^{3} \frac{\partial \delta}{\partial a} d a \\
& +\int_{\delta_{A \max }}^{\delta_{0}}\left(\frac{4 E^{*}}{3 r_{1}} a^{3}-2 \pi \Delta \gamma^{*} r_{1}\right) \frac{\partial \delta}{\partial a} d a \\
= & 2 \pi \Delta \gamma^{*} r_{1}\left(\frac{3 \pi r_{1}^{2} \Delta \gamma^{*}}{2 E_{A}{ }^{*}}\right)^{2 / 3} \\
= & 17.66 \Delta \gamma^{* 5 / 3} E_{A}^{*-2 / 3} r_{1}^{4 / 3} .
\end{aligned}
$$

According to the collision theory, the damping force during the collision is proportional to the instantaneous velocity of the particle. If we only consider the damping energy loss, the damping force is greater due to the higher particle 

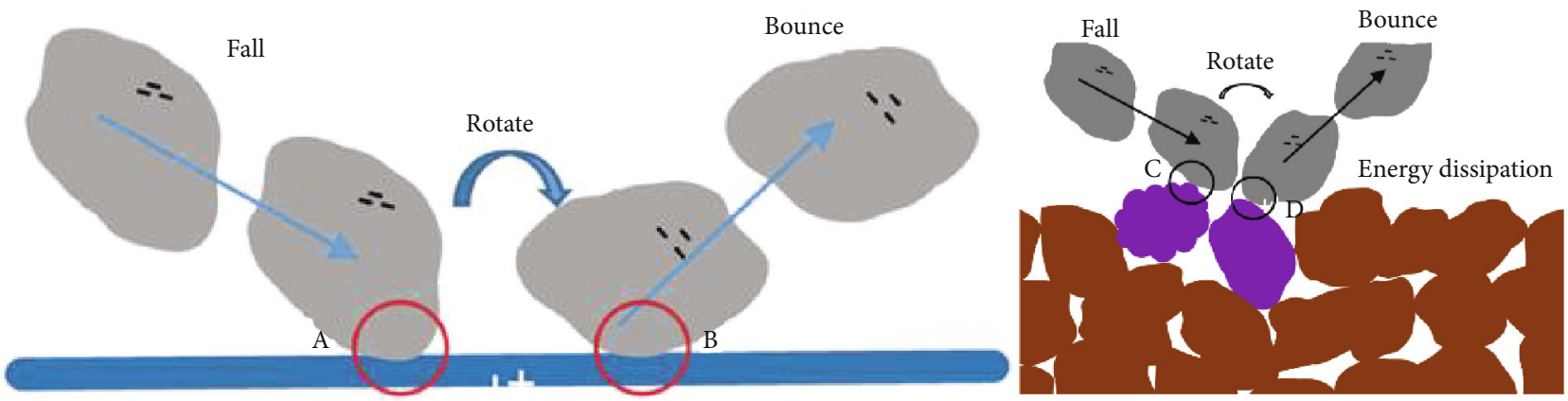

FIGURE 4: Deposition process of Martian dust particles.

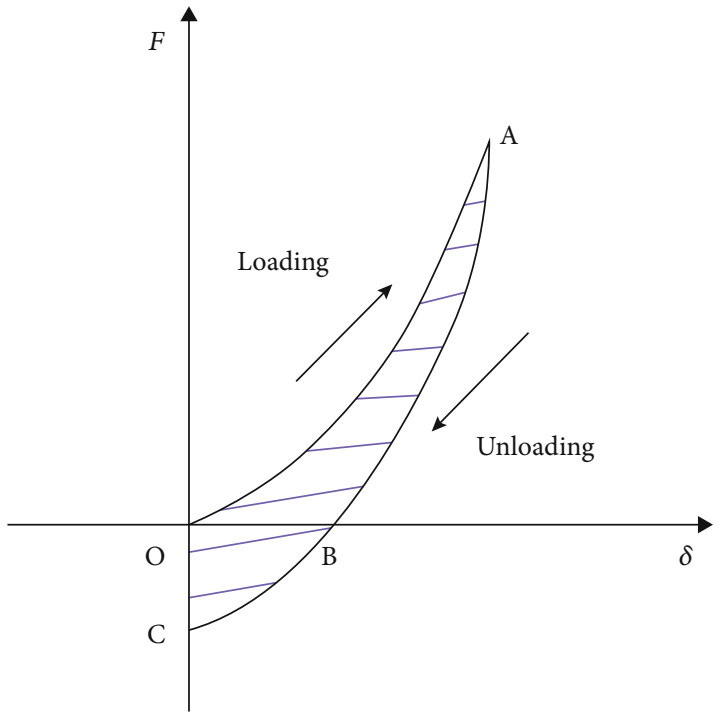

Figure 5: Comparison of Opportunity's solar panels before and after the MY28 GDS.

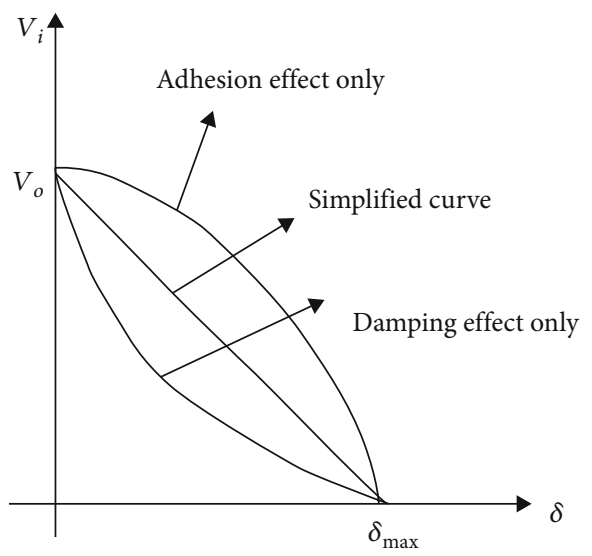

FIGURE 6: Simplification of the velocity-normal displacement curve.

velocity at the beginning of the collision process, which causes a lower deceleration rate during the collision process. If we only consider the adhesion energy loss, the adhesion force is smaller due to the smaller normal displacement at the beginning of the collision process, which causes a higher deceleration rate during the collision process. Considering the coupling effect of the adhesion energy loss and the damping energy loss, the relationship between the particle velocity and the normal displacement can be simplified as a linear curve, which is shown in Figure 6.

Thus, the damping energy loss at the first contact point $\mathrm{A}$ can be calculated as follows.

$$
\begin{aligned}
W_{A d} & =\int_{\delta_{0}}^{\delta_{A \max }} C V_{i} d \delta=\frac{1}{2} C V_{0}\left(\frac{3 \pi r_{1}^{2} \Delta \gamma^{*}}{2 E_{A}{ }^{*}}\right)^{2 / 3} \\
& =1.41 C \Delta \gamma^{* 2 / 3} E_{A}{ }^{*-2 / 3} r_{1}{ }^{1 / 3} V_{0} .
\end{aligned}
$$

In equation (6), $C$ is the damping coefficient, and $V_{0}$ is the initial particle velocity during the collision process.

According to equation (5) and equation (6), the total energy dissipation of the Martian dust particle at the first contact point A can be calculated as follows.

$$
\begin{aligned}
W_{A}= & W_{A v}+W_{A d}=17.66 \Delta \gamma^{* 5 / 3} E_{A}{ }^{*-2 / 3} r_{1}{ }^{4 / 3} \\
& +1.41 C \Delta \gamma^{* 2 / 3} E_{A}{ }^{*-2 / 3} r_{1}{ }^{1 / 3} V_{0} .
\end{aligned}
$$

According to Figure 4, the particle collides with the Martian rover's surface at the second contact point $B$ after rotating a certain angle. $R_{1}=r_{2}$ is the curvature radius of the contact point $\mathrm{B}$, and $R_{2}$ is the curvature radius of the surface. Thus,

$$
R_{1}^{*}=\left.\frac{R_{1} R_{2}}{R_{1}+R_{2}}\right|_{R_{1}=r_{2}, R_{2}=+\infty}=r_{2} .
$$

The adhesion energy loss at the contact point B of the second collision can be calculated as follows.

$$
\begin{aligned}
W_{B v}= & \int_{\delta_{0}}^{\delta_{B \max }} \frac{4 E^{*}}{3 r_{2}} a^{3} \frac{\partial \delta}{\partial a} d a \\
& +\int_{\delta_{B \max }}^{\delta_{0}}\left(\frac{4 E^{*}}{3 r_{2}} a^{3}-2 \pi \Delta \gamma^{*} r_{2}\right) \frac{\partial \delta}{\partial a} d a \\
= & 2 \pi \Delta \gamma^{*} r_{2}\left(\frac{3 \pi r_{2}^{2} \Delta \gamma^{*}}{2 E_{A}{ }^{*}}\right)^{2 / 3} \\
= & 17.66 \Delta \gamma^{* 5 / 3} E_{B}{ }^{*-2 / 3} r_{2}{ }^{4 / 3} .
\end{aligned}
$$


The damping energy loss at the second contact point B can be calculated as follows.

$$
\begin{aligned}
W_{B d} & =\int_{\delta_{0}}^{\delta_{B \max }} C V_{i} d \delta=\frac{1}{2} C V_{B 0}\left(\frac{3 \pi r_{2}^{2} \Delta \gamma^{*}}{2 E_{B}{ }^{*}}\right)^{2 / 3} \\
& =2 C \Delta \gamma^{* 2 / 3} E_{B}{ }^{*-2 / 3} r_{2}^{1 / 3} m^{-1 / 2} \Delta W_{B}{ }^{1 / 2} .
\end{aligned}
$$

In equation (10), $\Delta W_{B}=1 / 2 m V_{0}^{2}-W_{A}$ is the initial kinetic energy at the contact point $B$.

According to equation (9) and equation (10), the total energy dissipation of the Martian dust particle at the second contact point $\mathrm{B}$ can be calculated as follows.

$$
\begin{aligned}
W_{B}= & W_{B v}+W_{B d}=17.66 \Delta \gamma^{* 5 / 3} E_{B}{ }^{*-2 / 3} r_{2}{ }^{4 / 3} \\
& +2 C \Delta \gamma^{* 2 / 3} E_{B}{ }^{*-2 / 3} r_{2}^{1 / 3} m^{-1 / 2} \Delta W_{B}{ }^{1 / 2} .
\end{aligned}
$$

Therefore, the total energy dissipation of the particleMartian rover collision is

$$
W_{A B}=W_{A}+W_{B} .
$$

While analyzing the collision between the Martian dust particle and the grain bed, $R_{1}=r_{C 1}$ is the curvature radius of the depositing particle at the first contact point $\mathrm{C}$, and $R_{2}=r_{C 2}$ is the curvature radius of the grain bed particle at the contact point $\mathrm{C}$. Thus,

$$
R_{C}^{*}=\left.\frac{R_{1} R_{2}}{R_{1}+R_{2}}\right|_{R_{1}=r_{C 1}, R_{2}=r_{C 2}}=\frac{r_{C 1} r_{C 2}}{r_{C 1}+r_{C 2}} .
$$

The adhesion energy loss at the contact point $\mathrm{C}$ of the first collision can be calculated as follows.

$$
\begin{aligned}
W_{C v}= & \int_{\delta_{0}}^{\delta_{C \max }} \frac{4 E^{*}}{3 R_{C}^{*}} a^{3} \frac{\partial \delta}{\partial a} d a \\
& +\int_{\delta_{C \max }}^{\delta_{0}}\left(\frac{4 E^{*}}{3 R_{C}^{*}} a^{3}-2 \pi \Delta \gamma^{*} R_{C}^{*}\right) \frac{\partial \delta}{\partial a} d a \\
= & 2 \pi \Delta \gamma^{*} R_{C}^{*}\left(\frac{3 \pi R_{C}^{* 2} \Delta \gamma^{*}}{2 E_{p}^{*}}\right)^{2 / 3} \\
= & 17.66 \Delta \gamma^{* 5 / 3} E_{p}^{*-2 / 3} R_{C}^{* 4 / 3} .
\end{aligned}
$$

The damping energy loss at the first contact point $\mathrm{C}$ can be calculated as follows.

$$
W_{C d}=\int_{\delta_{0}}^{\delta_{C \max }} C V_{i} d \delta=1.41 C \Delta \gamma^{* 2 / 3} E_{p}{ }^{*-2 / 3} R_{C}^{* 1 / 3} V_{0} .
$$

According to equation (14) and equation (15), the total energy dissipation of the Martian dust particle at the first contact point $\mathrm{C}$ can be calculated as follows.

$$
\begin{aligned}
W_{C}= & W_{C v}+W_{C d}=17.66 \Delta \gamma^{* 5 / 3} E_{p}{ }^{*-2 / 3} R_{C}^{* 4 / 3} \\
& +1.41 C \Delta \gamma^{* 2 / 3} E_{p}{ }^{*-2 / 3} R_{C}^{* 1 / 3} V_{0} .
\end{aligned}
$$

TABle 1: Parameters of Martian dust materials and Martian rover materials.

\begin{tabular}{lc}
\hline Parameters & Value \\
\hline Curvature radius of the contact point $r$ & $10^{-7} \mathrm{~m}$ \\
Combined radius of Martian dust particles $R^{*}$ & $5 \sim 100 \mu \mathrm{m}$ \\
Shear modulus of Martian dust particles & $20 \mathrm{GPa}$ \\
Poisson's ratio of Martian dust particles & 0.25 \\
Shear modulus of Martian rover materials & $70 \mathrm{GPa}$ \\
Poisson's ratio of Martian rover materials & 0.3 \\
Surface energy between the particles and the & $0.04 \mathrm{~J} / \mathrm{m}^{2}$ \\
Martian rover $\Delta \gamma^{*}$ & \\
\hline
\end{tabular}

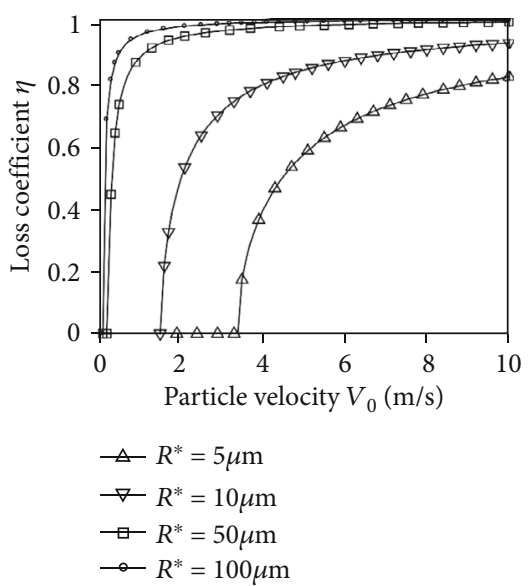

Figure 7: The effect of the combined radius $R^{*}$ to the critical wind speed $V_{c 1}$.

According to Figure 4, the particle collides with the grain bed at the second contact point $\mathrm{D}$ after rotating a certain angle. The adhesion energy loss $W_{D v}$ and the damping energy loss $W_{D d}$ at the second contact point $\mathrm{D}$ can be calculated as follows.

$$
\begin{aligned}
W_{D v}= & \int_{\delta_{0}}^{\delta_{D \max }} \frac{4 E^{*}}{3 R_{D}^{*}} a^{3} \frac{\partial \delta}{\partial a} d a \\
& +\int_{\delta_{D \max }}^{\delta_{0}}\left(\frac{4 E^{*}}{3 R_{D}^{*}} a^{3}-2 \pi \Delta \gamma^{*} R_{D}^{*}\right) \frac{\partial \delta}{\partial a} d a \\
= & 2 \pi \Delta \gamma^{*} R_{D}^{*}\left(\frac{3 \pi R_{D}^{* 2} \Delta \gamma^{*}}{2 E_{p}^{*}}\right)^{2 / 3} \\
= & 17.66 \Delta \gamma^{* 5 / 3} E_{p}^{*-2 / 3} R_{D}^{* 4 / 3}, \\
W_{D d}= & \int_{\delta_{0}}^{\delta_{D \max }} C V_{i} d \delta \\
= & 2 C \Delta \gamma^{* 2 / 3} E_{P}{ }^{*-2 / 3} R_{D}^{* 1 / 3} m^{-1 / 2} \Delta W_{D}{ }^{1 / 2} .
\end{aligned}
$$

In equation (18), $\Delta W_{D}=1 / 2 m V_{0}^{2}-W_{C}$ is the initial kinetic energy at the contact point $\mathrm{D}$. 


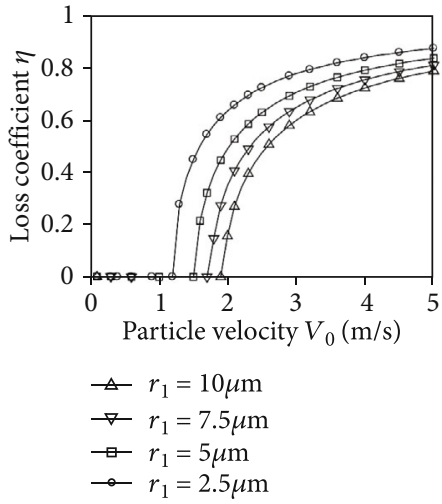

(a)

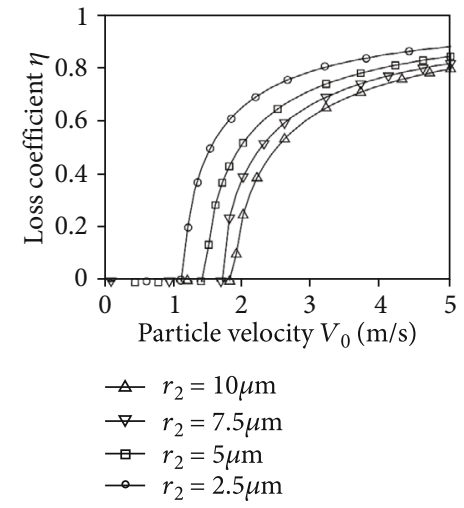

(b)

FIgUre 8: The effect of the curvature radii to the critical wind speed $V_{c 1}$ : (a) The effect of $r_{1}$ to the $V_{c 1}$; (b) The effect of $r_{2}$ to the $V_{c 1}$.

According to equation (17) and equation (18), the total energy dissipation of the Martian dust particle at the second contact point $\mathrm{D}$ can be calculated as follows.

$$
\begin{aligned}
W_{D}= & W_{D v}+W_{D d}=17.66 \Delta \gamma^{* 5 / 3} E_{p}{ }^{*-2 / 3} R_{D}^{* 4 / 3} \\
& +2 C \Delta \gamma^{* 2 / 3} E_{P}{ }^{*-2 / 3} R_{D}^{* 1 / 3} m^{-1 / 2} \Delta W_{D}{ }^{1 / 2}
\end{aligned}
$$

Therefore, the total energy dissipation of the particlegrain bed collision is

$$
W_{C D}=W_{C}+W_{D}
$$

\subsection{Critical Wind Speed for Martian Dust Particle Deposition} Process. If the initial energy of the Martian dust particle is greater than the energy dissipation during the collision process, the falling particle will bounce from the Martian rover's surface or the grain bed after the collision process. In this paper, we define the critical wind speed for the deposition process is the maximum velocity for the particle that rests on the Martian rover's surface or the grain bed after the collision process. Thus, the critical wind speed for the deposition process on the Martian rover's surface $V_{c 1}$ should meet the following rules.

$$
\left\{\begin{array}{l}
W_{A}=W_{A v}+W_{A d}=17.66 \Delta \gamma^{* 5 / 3} E_{A}{ }^{*-2 / 3} r_{1}{ }^{4 / 3}+1.41 C \Delta \gamma^{* 2 / 3} E_{A}{ }^{*-2 / 3} r_{1}{ }^{1 / 3} V_{c 1}, \\
\Delta W_{B}=\frac{1}{2} m V_{c 1}{ }^{2}-W_{A}=W_{B}, \\
\frac{1}{2} m V_{c 1}{ }^{2}=W_{A}+17.66 \Delta \gamma^{* 5 / 3} E_{B}{ }^{*-2 / 3} r_{2}{ }^{4 / 3}+2 C \Delta \gamma^{* 2 / 3} E_{B}{ }^{*-2 / 3} r_{2}^{1 / 3} m^{-1 / 2} \Delta W_{B}{ }^{1 / 2} .
\end{array}\right.
$$

We assume $g_{1}=17.66 \Delta \gamma^{* 5 / 3} E_{A}{ }^{*-2 / 3} r_{1}^{4 / 3}, g_{2}=1.41 C \Delta$ $\gamma^{* 2 / 3} E_{A}{ }^{*-2 / 3} r_{1}{ }^{1 / 3}, g_{3}=1 / 2 m, g_{4}=17.66 \Delta \gamma^{* 5 / 3} E_{B}{ }^{*-2 / 3} r_{2}{ }^{4 / 3}$, $g_{5}=2 C \Delta \gamma^{* 2 / 3} E_{B}{ }^{*-2 / 3} r_{2}^{1 / 3} m^{-1 / 2}$, then, $V_{c 1}$ can be calculated as follows.

$$
\left\{\begin{array}{l}
V_{c 1}=\frac{g_{2}+\sqrt{g_{2}^{2}+4 g_{3}\left(g_{1}+\Delta W_{B}\right)}}{2 g_{3}}, \\
\Delta W_{B}=\frac{1}{4}\left(g_{5}+\sqrt{4 g_{4}+g_{5}^{2}}\right)^{2}
\end{array}\right.
$$

In the above equations, $g_{1}$ is the coefficient of the adhesion energy loss at the contact point A, $g_{2}$ is the coefficient of the damping energy loss at the contact point $\mathrm{A}$, $g_{3}$ is the coefficient of the kinetic energy, $g_{4}$ is the coefficient of the adhesion energy loss at the contact point B, and $g_{5}$ is the coefficient of the damping energy loss at the contact point $\mathrm{B}$.

Similarly, the critical wind speed for the deposition process on the grain bed $V_{c 2}$ should meet the following rules.

$$
\left\{\begin{array}{l}
W_{C}=W_{C v}+W_{C d}=17.66 \Delta \gamma^{* 5 / 3} E_{p}{ }^{*-2 / 3} R_{C}^{* 4 / 3}+1.41 C \Delta \gamma^{* 2 / 3} E_{p}{ }^{*-2 / 3} R_{C}^{* 1 / 3} V_{c 2}, \\
\Delta W_{D}=\frac{1}{2} m V_{c 2}{ }^{2}-W_{C}=W_{D}, \\
\frac{1}{2} m V_{c 2}{ }^{2}=W_{C}+17.66 \Delta \gamma^{* 5 / 3} E_{p}{ }^{*-2 / 3} R_{D}^{* 4 / 3}+2 C \Delta \gamma^{* 2 / 3} E_{P}{ }^{*-2 / 3} R_{D}^{* 1 / 3} m^{-1 / 2} \Delta W_{D}{ }^{1 / 2} .
\end{array}\right.
$$



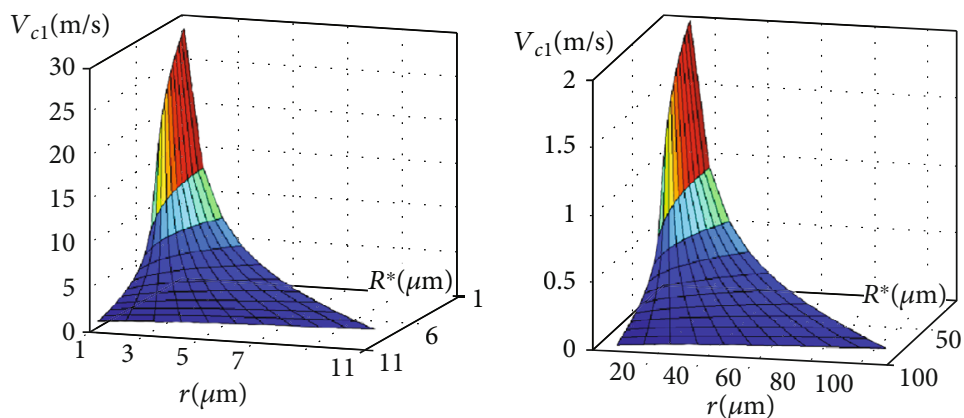

FIgURE 9: Surface diagram of the critical wind speed $V_{c 1}$.
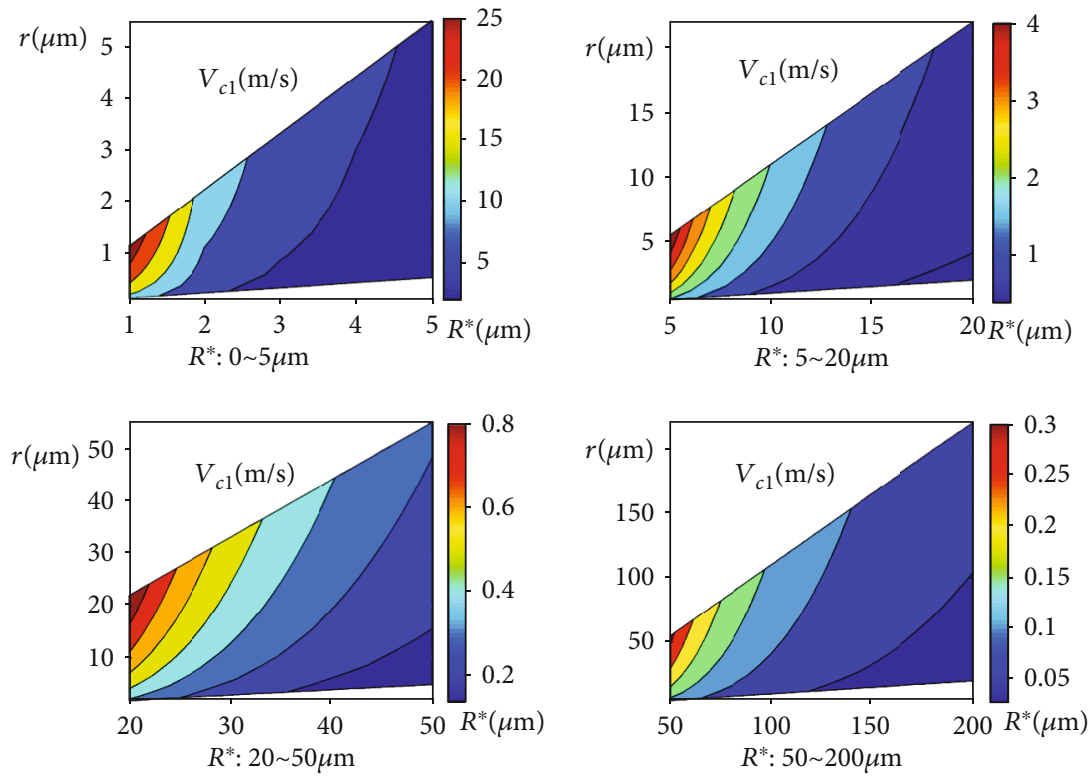

Figure 10: Contour map of the critical wind speed $V_{c 1}$.

TABle 2: Parameters of Martian dust materials.

\begin{tabular}{lc}
\hline Parameter & Value \\
\hline Curvature radius of the contact point $r$ & $10^{-7} \mathrm{~m}$ \\
Combined radius of Martian dust particles $R^{*}$ & $5 \sim 100 \mu \mathrm{m}$ \\
Shear modulus of Martian dust particles & $20 \mathrm{GPa}$ \\
$\begin{array}{l}\text { Poisson's ratio of Martian dust particles } \\
\text { Surface energy between the falling particles } \\
\text { and the grain bed particles } \Delta \gamma^{*}\end{array}$ & 0.25 \\
\hline
\end{tabular}

We assume $h_{1}=17.66 \Delta \gamma^{* 5 / 3} E_{p}{ }^{*-2 / 3} R_{C}^{* 4 / 3}, h_{2}=1.41 C \Delta$ $\gamma^{* 2 / 3} E_{P}{ }^{*-2 / 3} R_{C}^{* 1 / 3}, \quad h_{3}=1 / 2 m, \quad h_{4}=17.66 \Delta \gamma^{* 5 / 3} E_{p}{ }^{*-2 / 3} R_{D}^{* 4 / 3}$, $h_{5}=2 C \Delta \gamma^{* 2 / 3} E_{p}{ }^{*-2 / 3} R_{D}^{* 1 / 3} m^{-1 / 2}$, then, $V_{c 2}$ can be calculated as follows.

$$
\left\{\begin{array}{l}
V_{c 2}=\frac{h_{2}+\sqrt{h_{2}^{2}+4 h_{3}\left(h_{1}+\Delta W_{D}\right)}}{2 h_{3}}, \\
\Delta W_{D}=\frac{1}{4}\left(h_{5}+\sqrt{4 h_{4}+h_{5}^{2}}\right)^{2} .
\end{array}\right.
$$

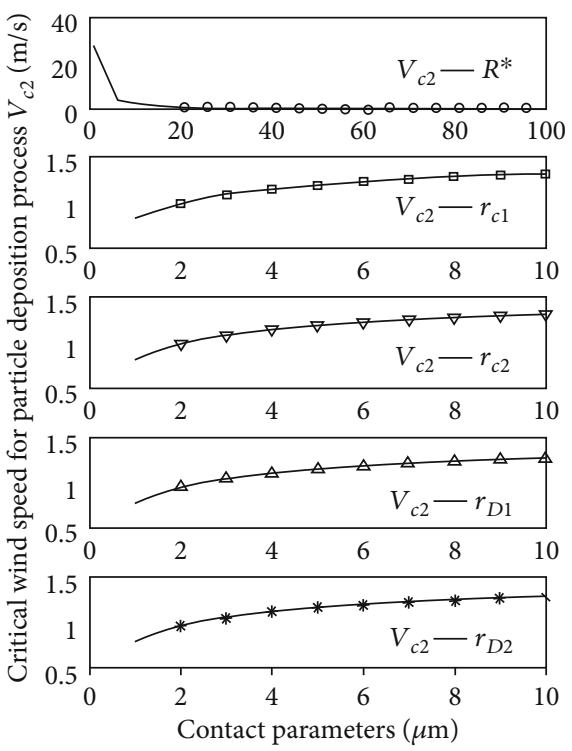

FIGURE 11: Effects of the contact parameters to the critical wind speed $V_{c 2}$. 

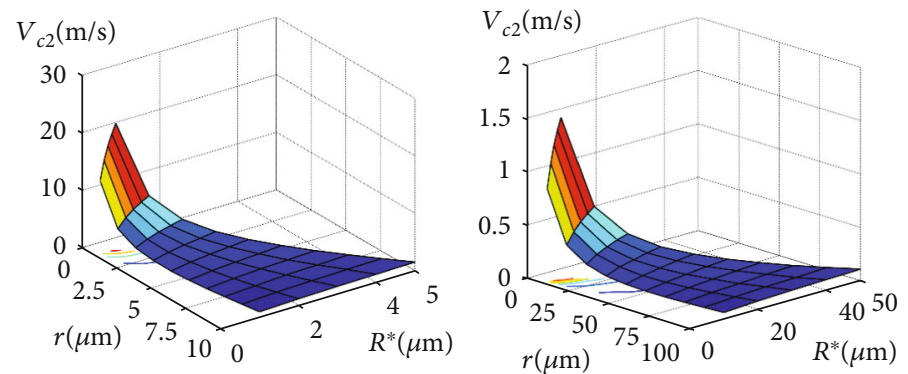

FIGURE 12: Surface diagram of the critical wind speed $V_{c 2}$.
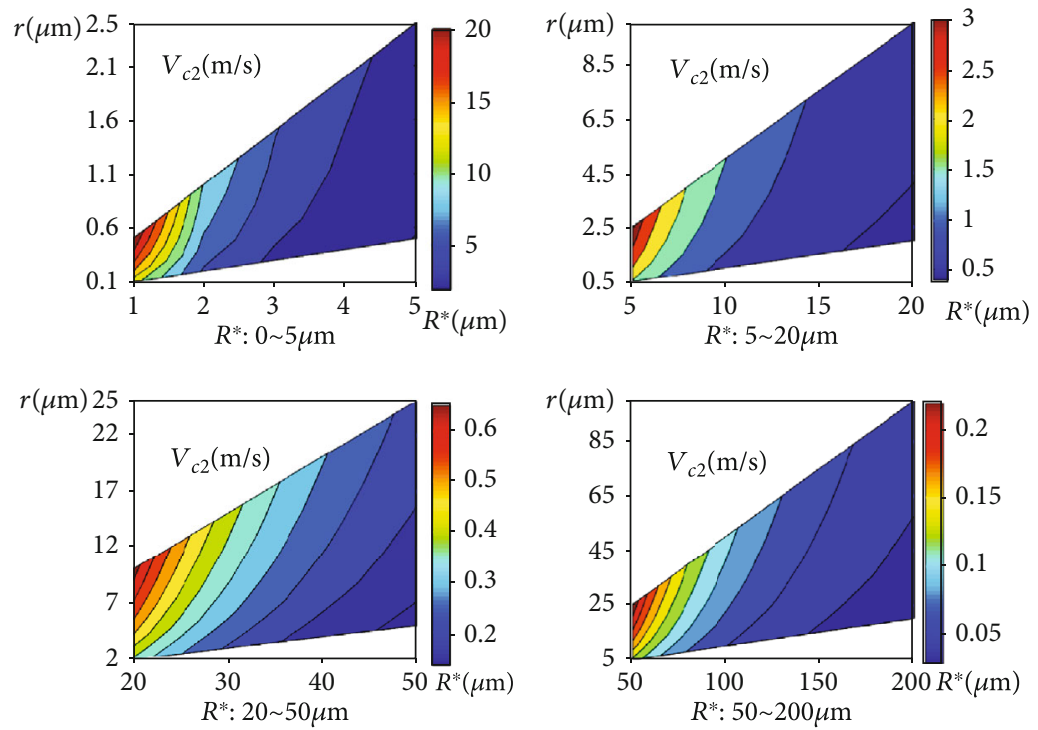

FIGURE 13: Contour map of the critical wind speed $V_{c 2}$.

TABLE 3: CFD simulation parameters of Martian airflow in Fluent.

\begin{tabular}{lc}
\hline Simulation parameters & Value \\
\hline Operating pressure & $690 \mathrm{pa}$ \\
Gravity & $3.73 \mathrm{~m} / \mathrm{s}^{2}$ \\
Temperature & $220 \mathrm{~K}$ \\
Density & $0.0167 \mathrm{~kg} / \mathrm{m}^{3}$ \\
Viscosity & $1.35 \times 10^{-5} \mathrm{kgm}^{-1} \mathrm{~s}^{-1}$ \\
Inlet velocity magnitude & $0.5 \sim 10 \mathrm{~m} / \mathrm{s}$ \\
Gauge pressure & $0 \mathrm{pa}$ \\
\hline
\end{tabular}

In the above equations, $h_{1}$ is the coefficient of the adhesion energy loss at the contact point $\mathrm{C}, h_{2}$ is the coefficient of the damping energy loss at the contact point $\mathrm{C}, h_{3}$ is the coefficient of the kinetic energy, $h_{4}$ is the coefficient of the adhesion energy loss at the contact point $\mathrm{D}$, and $h_{5}$ is the coefficient of the damping energy loss at the contact point D.

According to equation (22) and equation (24), the critical wind speed for the deposition process is the function of the combined radius of particles and the curvature radius of contact points. Due to the irregularly shaped characteristics of Martian dust particles, the combined radius and the curvature radius are diverse for different particles. Thus, the criti-

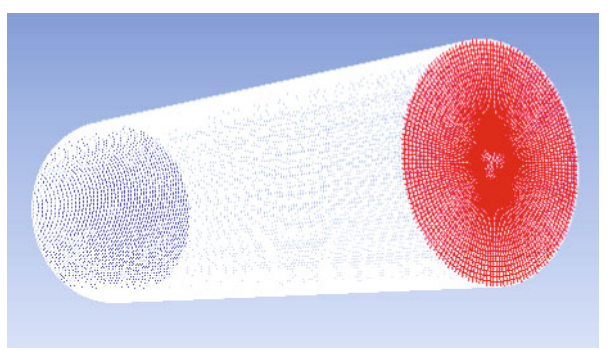

Figure 14: Mesh for the simulation of the Martian dust deposition process.

cal wind speed for the deposition process should be the random variable related to the combined radius and the curvature radius.

$V_{c 1}$ is the function of the combined radius $R^{*}$, the curvature radius of the falling particle at the contact point $\mathrm{A} r_{1}$ and the curvature radius of the falling particle at the contact point $\mathrm{B} r_{2} . X=\left[R^{*}, r_{1}, r_{2}\right]^{\mathrm{T}}$ is defined as the random vector of $V_{c 1}, f$ is the probability density function, $Z=\left[V_{c 1}, R^{*}, r_{1}, r_{2}\right]^{\mathrm{T}}$, thus,

$$
\left\{\begin{array}{l}
f_{Z}(Z)=f_{X}(X) \frac{1}{\left|J_{Z}(X)\right|}, \\
f_{X}(X)=f_{R^{*}}\left(R^{*}\right) f_{r_{1}}\left(r_{1}\right) f_{r_{2}}\left(r_{2}\right) .
\end{array}\right.
$$


In equation (25), $f_{X}(X)$ is the joint probability density of random independent variables, $J_{Z}(X)$ is the Jacobian determinant of the random vector $Z$ which is related to the random vector $X . J_{Z}(X)$ can be calculated as follows.

$$
J_{Z}(X)=\left|\begin{array}{lll}
\frac{\partial V_{c 1}}{\partial R^{*}} & \frac{\partial V_{c 1}}{\partial r_{1}} & \frac{\partial V_{c 1}}{\partial r_{2}} \\
\frac{\partial r_{1}}{\partial R^{*}} & \frac{\partial r_{1}}{\partial r_{1}} & \frac{\partial r_{1}}{\partial r_{2}} \\
\frac{\partial r_{2}}{\partial R^{*}} & \frac{\partial r_{2}}{\partial r_{1}} & \frac{\partial r_{2}}{\partial r_{2}}
\end{array}\right| .
$$

Thus, the probability density of $V_{c 1}$ is

$$
\left\{\begin{array}{l}
f_{V_{c 1}}\left(V_{c 1}\right)=\iint \frac{f_{X}(X)}{\left|J_{Z}(X)\right|} d r_{1} d r_{2}=\iint \frac{f_{R^{*}}\left(R^{*}\right) f_{r_{1}}\left(r_{1}\right) f_{r_{2}}\left(r_{2}\right)}{\partial V_{c 1} / \partial R^{*}} d r_{1} d r_{2}, \\
\frac{\partial V_{c 1}}{\partial R^{*}}=\frac{\partial V_{c 1}}{\partial g_{3}} \frac{\partial g_{3}}{\partial m} \frac{\partial m}{\partial R^{*}}+\frac{\partial V_{c 1}}{\partial \Delta W_{B}} \frac{\partial \Delta W_{B}}{\partial g_{5}} \frac{\partial g_{5}}{\partial m} \frac{\partial m}{\partial R^{*}} .
\end{array}\right.
$$

$V_{c 2}$ is the function of the combined radius $R^{*}$, the curvature radius of the falling particle at the contact point $\mathrm{C} r_{C 1}$, the curvature radius of the grain bed particle at the contact point $\mathrm{C} r_{\mathrm{C} 2}$, the curvature radius of the falling particle at
TABLE 4: DEM simulation parameters of Martian dust particles in EDEM.

\begin{tabular}{lc}
\hline Simulation parameters & Value \\
\hline $\begin{array}{l}\text { Poisson's ratio of the particles } v_{1} \\
\text { Shear modulus of the particles } G_{1}\end{array}$ & 0.25 \\
$2 \times 10^{10} \mathrm{pa}$ \\
$\begin{array}{l}\text { Density of the particles } \rho_{1} \\
\text { Poisson's ratio of the Martian probe } v_{2}\end{array}$ & 0.3 \\
Shear modulus of the Martian probe $G_{2}$ & $7 \times 10^{10} \mathrm{pa}$ \\
$\begin{array}{l}\text { Density of the Martian probe } \rho_{2} \\
\text { Coefficient of friction between the particles } \\
\text { and the Martian probe } f\end{array}$ & $2719 \mathrm{~kg} / \mathrm{m}^{3}$ \\
$\begin{array}{l}\text { Coefficient of rolling friction between the } \\
\text { particles and the Martian probes } f_{R} \\
\text { Recovery coefficient between the particles } \\
\text { and the Martian probe } k_{0}\end{array}$ & 0.5 \\
$\begin{array}{l}\text { Surface energy between the particles and } \\
\text { the Martian probe } \gamma\end{array}$ & 0.01 \\
\hline
\end{tabular}

the contact point $\mathrm{D} r_{D 1}$, and the curvature radius of the grain bed particle at the contact point $\mathrm{D} r_{D 2}$. Thus, the probability density of $V_{c 2}$ can be calculated as follows.

$$
\left\{\begin{array}{l}
f_{V_{c 2}}\left(V_{c 2}\right)=\iiint \int \frac{f_{R^{*}}\left(R^{*}\right) f_{r_{C 1}}\left(r_{C 1}\right) f_{r_{C 2}}\left(r_{C 2}\right) f_{r_{D 1}}\left(r_{D 1}\right) f_{r_{D 2}}\left(r_{D 2}\right)}{\partial V_{c 2} / \partial R^{*}} d r_{C 1} d r_{D 1} d r_{C 2} r_{D 2}, \\
\frac{\partial V_{c 2}}{\partial R^{*}}=\frac{\partial V_{c 2}}{\partial h_{3}} \frac{\partial h_{3}}{\partial m} \frac{\partial m}{\partial R^{*}}+\frac{\partial V_{c 2}}{\partial \Delta W_{D}} \frac{\partial \Delta W_{D}}{\partial h_{5}} \frac{\partial h_{5}}{\partial m} \frac{\partial m}{\partial R^{*}} .
\end{array}\right.
$$

\section{Results and Discussion}

\subsection{Influence Factors of Critical Wind Speed for Martian Dust} Particles Deposition Process. While analyzing the collision between the rover's surface and the Martian dust particle, we use the Matlab to plot the $V_{c 1}$ curves in different combined radii $R^{*}$. Parameters of Martian dust materials and Martian rover materials are shown in Table 1. The coefficient of energy loss $\eta(0 \leq \eta \leq 1)$ is defined as the ratio of the particle velocity after collision to the particle velocity before the collision. It is obvious that the particle has a deposition process while $\eta=0$.

The effect of the combined radius $R^{*}$ to the critical wind speed $V_{c 1}$ is shown in Figure 7. It can be seen from Figure 7 that the $V_{c 1}$ grows substantially with the declining $R^{*}$. The coefficient of energy loss $\eta$ shows a truncation effect around the related critical wind speed.

The effect of the curvature radii $r_{1}, r_{2}$ at the contact point A and the contact point B to the critical wind speed $V_{c 1}$ are shown in Figure 8. It can be seen from Figure 8 that the $V_{c 1}$ rises with the growing curvature radius, while the adhesion energy loss is greater during the collision process.
Figures 9 and 10 are the surface diagram and the contour map of the $V_{c l}$, respectively. According to these two figures, we can estimate and compare the $V_{c 1}$ in different combined radii $R^{*}$ and curvature radii $r$.

While analyzing the collision between the grain bed and the Martian dust particle, we use the Matlab to plot the $V_{c 2}$ curves in different combined radii $R^{*}$ and curvature radii $r$. Parameters of Martian dust materials are shown in Table 2, while the effects of the contact parameters to the $V_{c 2}$ are shown in Figure 11. According to Figure 11, the combined radius of the particle shows a dominant influence on the critical wind speed $V_{c 2}$ while the curvature radii show similar influence on the $V_{c 2}$.

Figures 12 and 13 are the surface diagram and the contour map of the $V_{c 2}$, respectively. According to these two figures, we can estimate and compare the $V_{c 2}$ in different combined radii $R^{*}$ and curvature radii $r$.

3.2. Simulation of Martian Dust Deposition Process Based on DEM-CFD. A series of simulations of the Martian dust deposition process are performed by using the coupling module of EDEM-Fluent. Table 3 shows the CFD simulation 


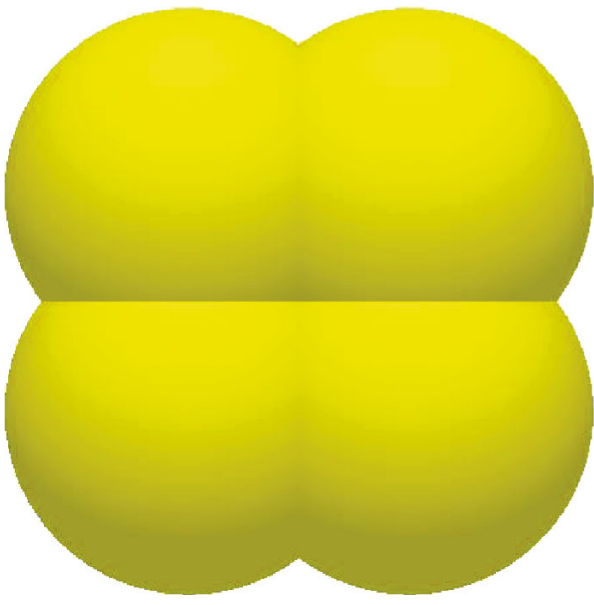

(a)

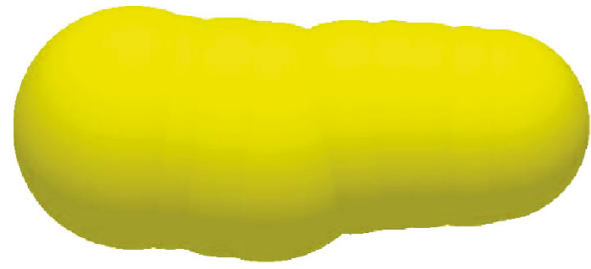

(c)

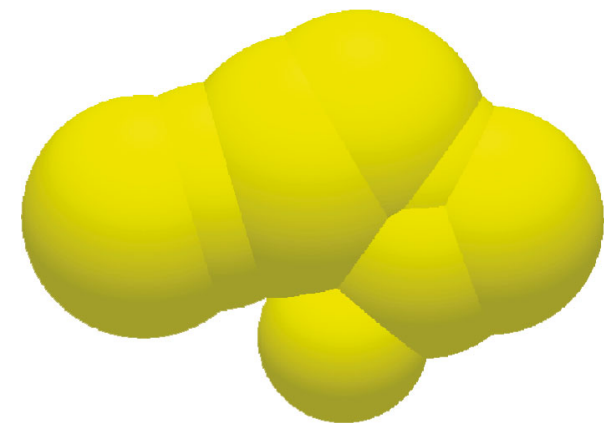

(b)

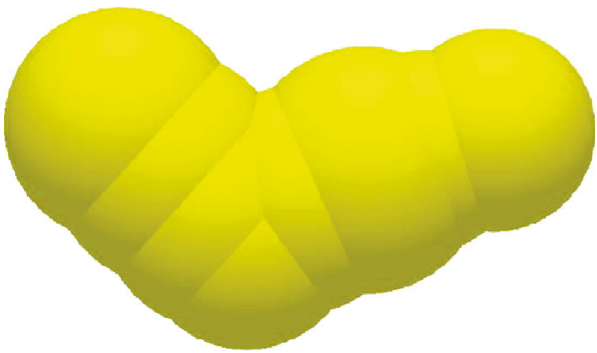

(d)

Figure 15: DEM models of Martian dust particles: (a) Fractal dimension 2.2; (b) Fractal dimension 2.3; (c) Fractal dimension 2.4; (d) Fractal dimension 2.5 .
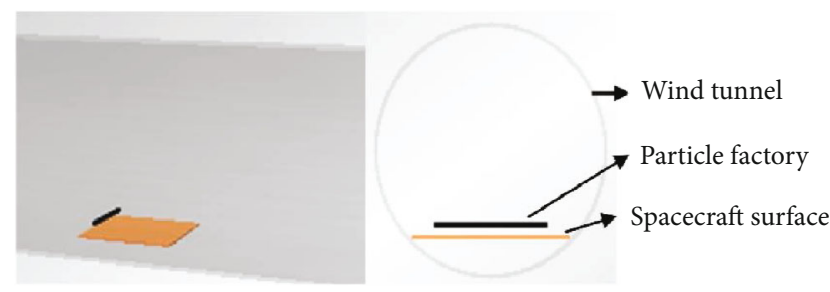

(a)

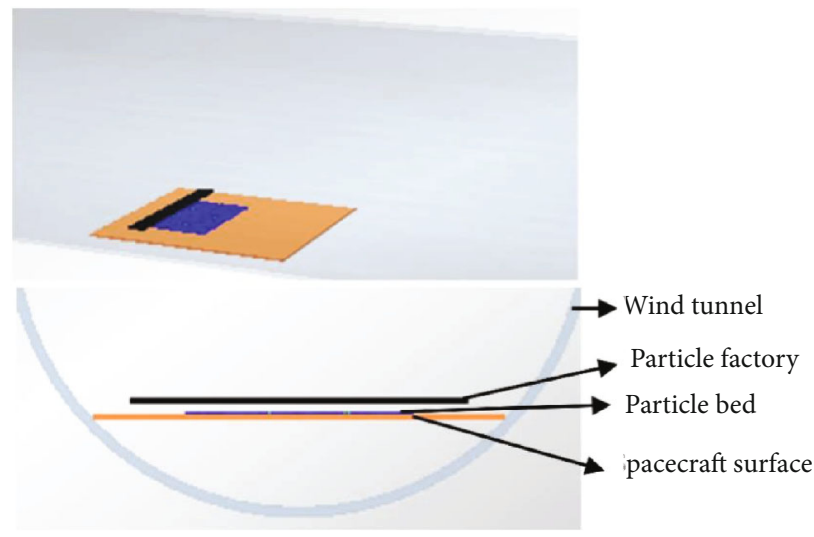

(b)

FIgURE 16: Simulation model for Martian dust deposition process: (a) Simulation model for particle-rover collision; (b) Simulation model for particle-particle collision. parameters of Martian airflow in Fluent. The velocity inlet and the pressure outlet are selected in the Fluent, and the simulation temperature is constant. The turbulence model is the RNG $\mathrm{k}-\varepsilon$ model. The mesh for the simulation is shown in Figure 14.

Martian dust particles are modeled in the Discrete Element Method (DEM) software EDEM, and simulation parameters of these particles are shown in Table 4. Since Martian dust particles have characteristics of irregular shape and tiny size, 4 kinds of particle models are modified with the fractal dimension of $2.2,2.3,2.4$, and 2.5 , respectively, which are shown in Figure 15 [36]. All these particles have the curvature radii of $1.78 \mu \mathrm{m} \sim 4.58 \mu \mathrm{m}$.

A series of simulations for the particle-rover collision and particle-particle collision are carried out for the study on the Martian dust deposition process, as shown in Figure 16. The particle factory is modified as the dynamic factory in order to generate new falling particles during the simulation process. In the simulation of particle-particle collision, particles are preplaced on the Martian rover's surface to simulate the grain bed, while these particles have a speed of less than $10^{-6} \mathrm{~m} / \mathrm{s}$.

The particles of fractal dimension 2.2 are used for analyzing the effect of the combined radius $R^{*}$ to the critical wind speed $V_{c 1}$ and $V_{c 2}$. The collision process between the $20 \mu \mathrm{m}$ sized particle and the Martian rover's surface is shown in Figure 17. According to the simulation result shown in Figure 17(a), the particle bounced back to the airflow after the collision process while the wind speed is $0.75 \mathrm{~m} / \mathrm{s}$. It can 


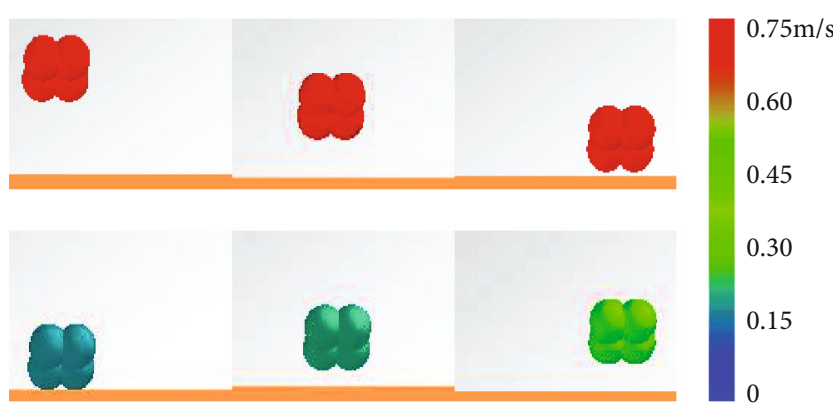

(a)

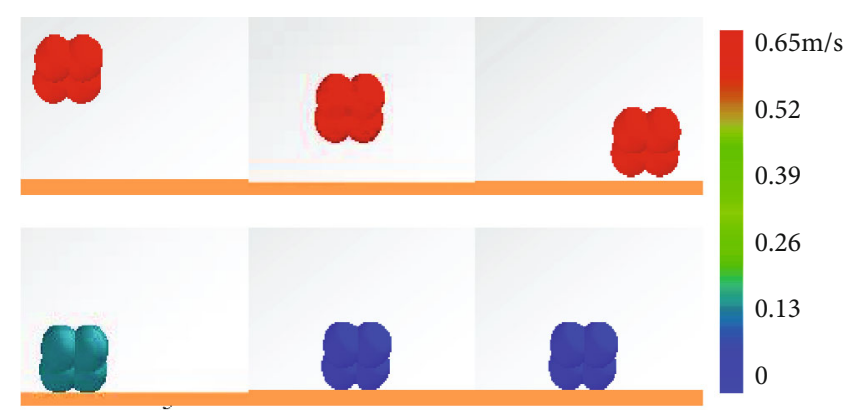

(b)

FIGURE 17: The collision process between the $20 \mu \mathrm{m}$ sized particle and the Martian rover's surface: (a) Bouncing process of the collision; (b) Deposition process of the collision.

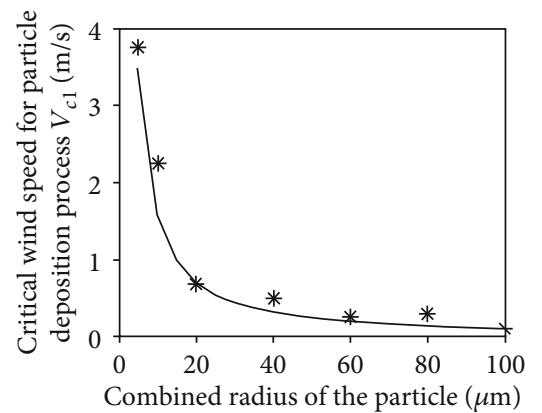

FIGURE 18: The simulation results and the theoretical results of the critical wind speed $V_{c 1}$.

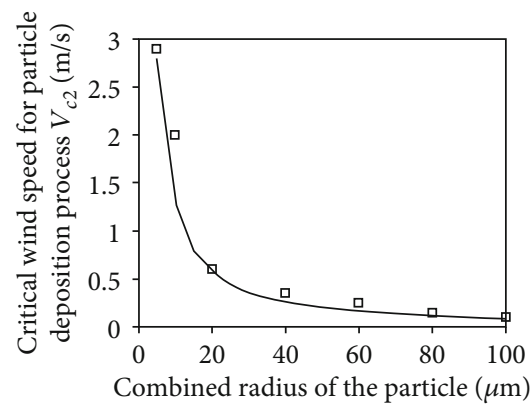

FIGURE 19: The simulation results and the theoretical results of the critical wind speed $V_{c 2}$.

be seen from Figure 17(b) that the particle deposited on the spacecraft surface after the collision process while the wind speed is $0.65 \mathrm{~m} / \mathrm{s}$. Therefore, the critical wind speed $V_{c 1}$ of this particle should be between $0.65 \mathrm{~m} / \mathrm{s}$ and $0.75 \mathrm{~m} / \mathrm{s}$. Based on this, we carried out a series of simulations with different wind speed conditions (from $0.65 \mathrm{~m} / \mathrm{s}$ to $0.75 \mathrm{~m} / \mathrm{s}$ ). Hence, the critical wind speed was defined as the maximum of these wind speed conditions based on DEM-CFD simulation results, in which the falling particle did not bounce back to the airflow. According to the simulation results, the critical wind speed $V_{c 1}$ of this particle is $0.68 \mathrm{~m} / \mathrm{s}$, which has a $7 \%$ error with the theoretical result $(0.73 \mathrm{~m} / \mathrm{s})$.

A series of simulations are carried out for analyzing the deposition process on the Marian rover's surface by using the fractal dimension 2.2 particles with the combined radii
TABLE 5: Distribution probability of the $V_{c 1}$ of the fractal dimension 2.3 particle.

\begin{tabular}{lccc}
\hline Number & $\begin{array}{c}\text { Curvature } \\
\text { radius }(\mu \mathrm{m})\end{array}$ & $\begin{array}{c}\text { Critical wind } \\
\text { speed }(\mathrm{m} / \mathrm{s})\end{array}$ & Probability (\%) \\
\hline 1 & 1.8 & 0.67 & 36 \\
2 & 2.5 & 0.78 & 35 \\
3 & 3.1 & 0.86 & 29 \\
\hline
\end{tabular}

TABLE 6: Distribution probability of the $V_{c 1}$ of the fractal dimension 2.5 particle.

\begin{tabular}{lccc}
\hline Number & $\begin{array}{c}\text { Curvature } \\
\text { radius }(\mu \mathrm{m})\end{array}$ & $\begin{array}{c}\text { Critical wind } \\
\text { speed }(\mathrm{m} / \mathrm{s})\end{array}$ & Probability (\%) \\
\hline 1 & 1.8 & 0.53 & 14 \\
2 & 2.5 & 0.67 & 15 \\
3 & 2.7 & 0.79 & 21 \\
4 & 3.2 & 0.96 & 35 \\
\hline
\end{tabular}

of $5 \mu \mathrm{m}, 10 \mu \mathrm{m}, 40 \mu \mathrm{m}, 60 \mu \mathrm{m}, 80 \mu \mathrm{m}$, and $100 \mu \mathrm{m}$, respectively. The simulation results and the theoretical results of the $V_{c 1}$ are shown in Figure 18. According to Figure 18, the critical wind speed $V_{c 1}$ drops significantly with the increasing combined radius, which proves that the smaller particles are more likely to be deposited on the Martian rover's surface. Besides, the errors between the simulation results (discrete data point) and the theoretical results (continuous curve) are less than $10 \%$, which proves the reliability of the theory.

The simulation results (discrete data point) and the theoretical results (continuous curve) for analyzing the deposition process on the grain bed by using the different sized fractal dimension 2.2 particles are shown in Figure 19. The results of the $V_{c 2}$ has a similar trend with the results of $V_{c 1}$, which also proves the reliability of the theory.

The $20 \mu \mathrm{m}$ sized particles in different shapes are used for analyzing the effect of different curvature radii to the critical wind speed $V_{c 1}$. Since curvature radii of the fractal dimension 2.2 particle and the fractal dimension 2.4 particle are too close, the fractal dimension 2.3 particle and the fractal dimension 2.5 particle are used for the simulation. The distribution probabilities of the $V_{c 1}$ of these two particles are 
shown in Tables 5 and 6 , respectively. It can be seen from Tables 5 and 6 that particles with a higher fractal dimension had a more dispersed probability of critical wind speed.

\section{Conclusions}

Based on the Discrete Element Method (DEM), the present study has established a contact model that includes the collision energy loss. This paper for the first time developed a method to study the energy dissipation of Martian dust particles after colliding with Martian rovers or the particle bed, which played an important role in the deposition process. Through the numerical approach, the combined radius of the particle showed a dominant influence on the critical wind speed for the particle deposition process, followed by curvature radii of contact points. Besides, particles with a higher fractal dimension had a more dispersed probability of critical wind speed. Importantly, this study provides a theoretical basis for Martian dust protection and the Martian exploration mission.

\section{Data Availability}

The data used to support the findings of this study are included within the article.

\section{Disclosure}

The extensive abstract of this paper was presented to The Inaugural International Symposium on Water Modelling (iSymWater2019) for an oral presentation. Thanks especially.

\section{Conflicts of Interest}

The authors declare that there are no conflicts of interest regarding the publication of this paper.

\section{Acknowledgments}

This research was funded by the National Nature Science Foundation of China (No. 51575123, No. 51902026), the Self-Planned Task (No. SKLRS201801B) of State Key Laboratory of Robot Technology and System (HIT), and the Qian Xuesen Laboratory of Space Technology Seed Fund (No. QXSZZJJ03-03).

\section{References}

[1] S. D. Guzewich, M. Lemmon, C. L. Smith et al., "Mars Science Laboratory Observations of the 2018/Mars Year 34 global Dust Storm," Geophysical Research Letters, vol. 46, no. 1, pp. 71-79, 2019.

[2] D. Viúdez-Moreiras, C. E. Newman, M. Torre et al., "Effects of the MY34/2018 Global Dust Storm as Measured by MSL REMS in Gale Crater," Journal of Geophysical Research: Planets, vol. 124, no. 7, pp. 1899-1912, 2019.

[3] M. E. Lisano and D. Bernard, "An Almanac of Martian Dust Storms for InSight project energy system design," Proceedings 2014 IEEE Aerospace Conference, 2014.
[4] R. J. McKim, "Telescopic Martian dust storms: a narrative and catalogue," vol. 44, Memoirs of the British Astronomical Association, 1999.

[5] R. W. Zurek and L. J. Martin, "Interannual variability of planet-encircling dust storms on Mars," Journal of Geophysical Research: Planets, vol. 98, no. E2, pp. 3247-3259, 1993.

[6] M. D. Smith, "THEMIS observations of Mars aerosol optical depth from 2002-2008," Icarus, vol. 202, no. 2, pp. 444-452, 2009.

[7] H. Wang and M. I. Richardson, "The origin, evolution, and trajectory of large dust storms on Mars during Mars years 24-30 (1999-2011)," Icarus, vol. 251, pp. 112-127, 2015.

[8] H. Y. McSween, G. J. Taylor, and M. B. Wyatt, "Elemental composition of the Martian crust," Science, vol. 324, no. 5928, pp. 736-739, 2009.

[9] H. Y. McSween Jr., I. O. McGlynn, and A. D. Rogers, "Determining the modal mineralogy of Martian soils," Journal of Geophysical Research: Planets, vol. 115, 2010.

[10] V. E. Hamilton, H. Y. McSween Jr., and B. Hapke, "Mineralogy of Martian atmospheric dust inferred from thermal infrared spectra of aerosols," Journal of Geophysical Research, vol. 110, no. E12, 2005.

[11] N. K. McKeown, J. L. Bishop, E. Z. Noe Dobrea et al., "Characterization of phyllosilicates observed in the central Mawrth Vallis region, Mars, their potential formational processes, and implications for past climate," Journal of Geophysical Research, vol. 114, 2009.

[12] A. S. Yen, R. Gellert, C. Schröder et al., "An integrated view of the chemistry and mineralogy of Martian soils," Nature, vol. 436, no. 7047, pp. 49-54, 2005.

[13] R. Greeley, S. W. Squyres, R. E. Arvidson et al., "Wind-related processes detected by the Spirit rover at Gusev crater, Mars," Science, vol. 305, no. 5685, pp. 810-813, 2004.

[14] R. Greeley, R. E. Arvidson, P. W. Barlett et al., "Gusev crater: Wind-related features and processes observed by the Mars Exploration Rover Spirit," Journal of Geophysical Research: Planets, vol. 111, no. E2, 2006.

[15] R. Sullivan, D. Banfield, J. F. Bell III et al., "Aeolian processes at the Mars exploration rover Meridiani Planum landing site," Nature, vol. 436, no. 7047, pp. 58-61, 2005.

[16] R. Sullivan, R. Arvidson, J. F. Bell III et al., "Wind-driven particle mobility on Mars: Insights from Mars Exploration Rover observations at "El Dorado" and surroundings at Gusev Crater," Journal of Geophysical Research, vol. 113, no. E6, 2008.

[17] M. Seibert, J. Herman, and D. ElDeeb, "Operations strategies for the Mars Exploration Rovers during the 2007 Martian global dust storm," Proceedings 2009 IEEE Aerospace conference, 2009.

[18] P. M. Stella and J. A. Herman, "The Mars surface environment and solar array performance. IEEE," Proceedings 2010 35th IEEE Photovoltaic Specialists Conference, 2010.

[19] J. Chen, K. Chu, R. Zou et al., "Systematic study of the effect of particle density distribution on the flow and performance of a dense medium cyclone," Powder Technology, vol. 314, pp. 510523, 2017.

[20] W. Zhong, A. Yu, X. Liu, Z. Tong, and H. Zhang, "DEM/CFDDEM modelling of non-spherical particulate systems: theoretical developments and applications," Powder Technology, vol. 302, pp. 108-152, 2016.

[21] Y. Shao, J. Gu, W. Zhong, and A. Yu, "Determination of minimum fluidization velocity in fluidized bed at elevated 
pressures and temperatures using CFD simulations," Powder Technology, vol. 350, pp. 81-90, 2019.

[22] J. Xie, W. Zhong, Y. Shao, and K. Li, "Coupling of CFD-DEM and reaction model for 3D fluidized beds," Powder Technology, vol. 353, pp. 72-83, 2019.

[23] S. Kuang, M. Zhou, and A. Yu, "CFD-DEM modelling and simulation of pneumatic conveying: A review," Powder Technology, vol. 365, pp. 186-207, 2020.

[24] Z. Miao, S. Kuang, H. Zughbi, and A. Yu, "CFD simulation of dilute-phase pneumatic conveying of powders," Powder Technology, vol. 349, pp. 70-83, 2019.

[25] Q. F. Hou, S. B. Kuang, and A. B. Yu, “A DEM-based approach for analyzing energy transitions in granular and particle-fluid flows," Chemical Engineering Science, vol. 161, pp. 67-79, 2017.

[26] S. Kuang, Z. Li, and A. Yu, "Review on Modeling and Simulation of Blast Furnace," steel research international, vol. 89, no. 1, p. 1700071, 2018.

[27] L. W. Rong, K. J. Dong, and A. B. Yu, “A general solution of the drag force in packed beds of multi-sized particles under creeping fluid flow conditions," Powder Technology, vol. 315, pp. 87-97, 2017.

[28] K. W. Chu, J. Chen, B. Wang et al., "Understand solids loading effects in a dense medium cyclone: effect of particle size by a CFD-DEM method," Powder Technology, vol. 320, pp. 594609, 2017.

[29] K. W. Chu, S. B. Kuang, Z. Y. Zhou, and A. B. Yu, "Model A vs. Model B in the modelling of particle-fluid flow," Powder Technology, vol. 329, pp. 47-54, 2018.

[30] C. Pei, C. Y. Wu, and M. Adams, "DEM-CFD analysis of contact electrification and electrostatic interactions during fluidization," Powder Technology, vol. 304, pp. 208-217, 2016.

[31] C. Pei, C. Y. Wu, D. England, S. Byard, H. Berchtold, and M. Adams, "DEM-CFD modeling of particle systems with long-range electrostatic interactions," AICHE Journal, vol. 61, no. 6, pp. 1792-1803, 2015.

[32] C. Pei, C. Y. Wu, D. England, S. Byard, H. Berchtold, and M. Adams, "Numerical analysis of contact electrification using DEM-CFD," Powder Technology, vol. 248, pp. 34-43, 2013.

[33] X. Hou, T. Ding, T. Chen, Y. Liu, M. Li, and Z. Deng, "Constitutive properties of irregularly shaped lunar soil simulant particles," Powder Technology, vol. 346, pp. 137-149, 2019.

[34] B. V. Derjaguin, V. M. Muller, and Y. P. Toporov, "Effect of contact deformations on the adhesion of particles," Journal of Colloid and Interface Science, vol. 53, no. 2, pp. 314-326, 1975.

[35] D. Maugis, "Adhesion of spheres: the JKR-DMT transition using a Dugdale model," Journal of Colloid and Interface Science, vol. 150, no. 1, pp. 243-269, 1992.

[36] X. Hou, T. Ding, Z. Deng et al., "Study of the creeping of irregularly shaped Martian dust particles based on DEM-CFD," Powder Technology, vol. 328, pp. 184-198, 2018. 